\title{
Desejo de performance na arena discursiva da desprofissionalização docente
}

\author{
Desire of performance in the discursive field on teachers' deprofessionalization \\ Deseo de rendimmiento em la arena discursiva de la desprofessionalización docente
}

Recebido: 05/01/2021 | Revisado: 06/01/2021 | Aceito: 13/01/2021 | Publicado: 17/01/2021
Letícia Ramalho Brittes
ORCID: https://orcid.org/0000-0002-0279-2713
Instituto Federal de Educação, Ciência e Tecnologia Farroupilha, Brasil
E-mail: brittesleticia @ gmail.com
Joacir Marques da Costa
ORCID: https://orcid.org/0000-0002-6099-7186
Universidade Federal de Santa Maria, Brasil
E-mail: mc.joacir@gmial.com
Cléber Lixinski de Lima
ORCID: https://orcid.org/0000-0002-4232-8472
E-mail: cleberlixinski@gamial.com

\begin{abstract}
Resumo
O princípio da gestão democrática no sistema educacional brasileiro avança, discursivamente, mediante direcionamentos da Constituição Federal de 1988 e da Lei de Diretrizes e Bases n ${ }^{\circ}$ 9.394/96, o que, de certo modo, movimenta re/configurações do trabalho docente. E é a partir desse contexto que repousa o presente estudo, tendo como interesse problematizar como o enfoque democrático/neoliberal e suas dissoluções de sentidos têm operado paralelamente à cultura da performatividade, delineando novos papéis e novos perfis para o trabalho docente. Para tanto, realizou-se uma pesquisa de cunho bibliográfico para subsidiar a discussão em torno das noções de trabalho, gestão e da arena discursiva global e local das políticas educacionais. Concluiu-se que, quando uma cultura performativa opera sobre o trabalho docente, desencadeiam-se sentidos de desprofissionalização, atrelados, sobretudo, a um processo de autonomia imaginada, o que poderá gerar maior controle e adesão por parte do professorado às políticas de responsabilização docente. Nesse sentido, o professor é peça fundamental para o funcionamento discursivo das políticas, haja vista o possível engajamento desse sujeito relacionado, tanto, ao desejo de performance, quanto, para delinear os rumos da recontextualização dessas políticas, as quais poderão conduzir ao sucesso e/ou fracasso escolares.
\end{abstract}

Palavras-chave: Gestão democrática; Neoliberalismo; Performatividade; Trabalho docente; Desprofissionalização.

\begin{abstract}
The principle of democratic management in the Brazilian educational system goes discursively foward by directions of the Federal Constitution of 1988 and the LDB - the main policy that guides Brazilian education - (Law 9.394/96) which moves new configurations for teachers' work. From that context this study intends to problematize how the democratic/neoliberal focus and its meaning dissolutions has working in parallel with the performatic culture, mapping new roles and new profiles to the teachers' work. To do that, we developed a bibliographic research to support the discussion on work, management, and global/ local discursive fields of educational policies. We conclude that when a performatic culture works over the teachers' work, it produces deprofessionalization meanings, which are linked, above all, to an imagined autonomy process that might generate bigger control and engagement of the teachers in the educational accountability policies. So, facing those problems, we can believe that the teacher is the fundamental keystone to promote discursive movements in the educational policies, considering their potential engagement as to performance desire as to design the ways to recontextualize those policies, which might lead them to the success or failure in educational process.
\end{abstract}

Keywords: Democratic management; Neoliberalism; Performativity; Teachers'work; Deprofessionalization.

\section{Resumen}

El principio de gestión democrática en el sistema educativo brasileño avanza, discursivamente, a instrucciones de la Constitución Federal de 1988 y la Ley de Directrices y Bases no 9.394 / 96, que, en cierto modo, se mueve re/configuración del trabajo docente. Y es a partir de este contexto que se encuentra el presente estudio, con el interés de cuestionar el enfoque democrático/neoliberal y sus disoluciones sentidos han operado en paralelo con la cultura de la performatividad, el esbozo de nuevas funciones y nuevos perfiles para el trabajo docente. Para este propósito, se llevó a cabo una investigación de carácter bibliográfico para apoyar la discusión sobre las y nociones de trabajo, la gestión y la arena discursiva global y local de las políticas educativas. Se concluyó que cuando una cultura 
performativa opera en el trabajo docente, se activan los sentidos de desprofesionalización, remolques, sobre todo, un proceso de autonomía imaginado, lo que podría conducir a un mayor control y aceptación por parte de los profesores a las políticas de rendición de cuentas docentes. En este sentido, el profesor es la clave para el funcionamiento discursivo de políticas, dada la posible implicación de este tema relacionado tanto con el deseo de rendimiento, como para delinear la recontextualización la dirección de estas políticas, lo que puede llevar al éxito y/o el fracaso escolar.

Palabras clave: Gestión democrática; Neoliberalismo; Performatividad; Trabajo docente; Desprofesionalización.

\section{Introdução}

Em meados dos anos de 1990, houve no Brasil o empreendimento de um processo de reformas de matriz neoliberal ${ }^{1}$, que resultou na minimização de compromissos ético-políticos e sociais firmados pelo Estado na Constituição de 1988 (Brasil, 1988). De uma maneira associada e subalterna, esse processo inseriu o Brasil no atual quadro hegemônico mundial, introduzindo um conjunto de "hábitos da educação privada e de suas sensibilidades comerciais e 'moral utilitária' na prática educacional" (Ball, 2004). Com isso, tais reformas adentraram-se nas políticas educacionais através da Lei de Diretrizes e Bases da Educação Nacional nº 9.394/96 (Brasil, 1996), desencadeando um procedimento educacional pulverizado e compensatório.

É nesse contexto que se inserem as atuais políticas públicas que organizam e escola e o trabalho docente, gerando uma série de contradições nos campos de atividades do setor público, provocando, segundo Ball, uma fragilidade nos papéis, nas identidades e nas relações de trabalho que estão sendo criadas em conformidade com essa lógica mercadológica (Ball, 2004). Segundo Ball (2004), ocorre, assim, a instauração de uma cultura de performatividade competitiva, a qual irá envolver e combinar descentralização, alvos e incentivos, produzindo novos perfis institucionais vinculados a um sistema de recompensas e sanções baseado na competição e na performatividade.

Nessa perspectiva, o presente artigo repousa na intenção de problematizar como o enfoque democrático/neoliberal e suas dissoluções de sentidos têm operado paralelamente à cultura da performatividade, delineando novos papéis e novos perfis para o trabalho docente. Para tanto, realizou-se uma pesquisa de cunho bibliográfico para subsidiar a discussão em torno das noções de trabalho, gestão e da arena discursiva global e local das políticas educacionais.

Doravante, o artigo organiza-se em três seções: esta que se apresenta como introdução que trata de "O trabalho docente na perspectiva da gestão democrática”, contextualizando as principais diretrizes que organizam o sistema educacional brasileiro em termos de proposta de gestão democrática e participativa e os efeitos desta sobre o trabalho docente, analisando as incompatibilidades entre os projetos hegemônicos atuantes em nossa conjuntura nacional: democrático e neoliberal; a seguir apresenta-se a discussão sobre "A imersão do trabalho docente na cultura da performatividade" que problematiza sobre como a performatividade funciona de diversas maneiras no intuito de criar novas identidades profissionais para os docentes, buscandose ainda investigar sobre como o Estado se insere profundamente nas culturas, práticas e subjetividades das instituições do setor público e de seus trabalhadores - aqui entendidos como empreendedores de si - sem parecer fazê-lo; na sequência tem-se a seção sobre "Autonomia imaginada e desprofissionalização docente" que sugere que o trabalho docente está alicerçado em uma frágil noção de autonomia, a qual se conceitua neste trabalho como imaginada, pois é revertida em precarização, intensificação e responsabilização docente, confluindo em um processo de desprofissionalização docente. Por fim, nas “Considerações finais" retoma-se alguns aspectos anteriormente discutidos no texto e se propõe a desarticulação do desejo de performance a partir do entendimento de que a profissionalização docente carece de novas significações e novas formas de existência que questionem aos imperativos neoconservadores e neoliberais.

\footnotetext{
${ }^{1}$ Conforme Harvey (2008, p.12), o neoliberalismo é em primeiro lugar uma teoria das práticas político-econômicas que propõe que o bemestar humano pode ser melhor promovido liberando-se as liberdades e capacidades empreendedoras individuais no âmbito de uma estrutura institucional caracterizada por sólidos direitos a propriedade privada, livres mercados e livres comércios.
} 


\section{Metodologia}

Selecionou-se para o estudo a pesquisa de natureza qualitativa, que se apresenta como uma abordagem própria para os estudos em educação, tendo em vista que propicia uma maior interação entre pesquisadores e os temas abordados, na medida que não se pauta por um rigor cartesiano absoluto. Ao contrário, permite ser modificada no percurso da pesquisa, garantindo que os sujeitos tenham primazia no desenvolvimento do trabalho. (Triviños, 2008).

Ademais, o estudo ora apresentado é uma pesquisa de cunho bibliográfico cuja construção é subsidiada na discussão em torno das noções de trabalho, gestão e da arena discursiva global e local das políticas educacionais. O artigo organiza-se em uma sistemática de produção de conhecimento. Criou-se uma sequência de fases, quais sejam: seleção do material mediante o critério da abordagem do tema em consonância com a perspectiva teórica escolhida, centrada em estudos relativos ao trabalho; leitura inicial com fichamento de ideias centrais; análise das categorias (palavras-chave) no material fichado; aprofundamento dos temas em novas leituras; e, por último, sistematização entremeando os estudos realizados com as descobertas e análises dos autores.

Como técnica de análise dos dados, utilizou-se a Análise Crítica de Discurso, com base em Fairclough (2001, 2004). Isso exigiu uma elaboração de dispositivos analíticos a priori e a análise delas lidas no material bibliográfico. Tal metodologia visou a impregnar nesta investigação um rigor científico marcado pela atenção aos detalhes, análise acurada dos dispositivos de análise e sistematização embasada nos estudos realizados até então.

\section{Resultados e Discussão}

\subsection{A imersão do trabalho docente na cultura da performatividade}

Ao encontro do que se discutiu até aqui, pode-se compreender que, no caso dos professores, constituindo-se em um modo de garantirem suas condições de existência, o trabalho configura-se "[...] no capitalismo, em uma das suas formas de expressão" (Kuenzer, 2002, p.82). Nesse sentido, a finalidade do trabalho pedagógico, como modalidade de trabalho na sociedade capitalista, "[...] é o disciplinamento para a vida social e produtiva, em conformidade com as especificidades que os processos de produção, em decorrência do desenvolvimento das forças produtivas, vão assumindo". O disciplinamento, neste viés de compreensão, implica o desenvolvimento de uma concepção de mundo tão consensual quanto seja possível (Kuenzer, 2002, p. 82), em acordo com as demandas e “[...] necessidades de valorização do capital” (Idem). E é nesse bojo que se desenvolvem as políticas educativas no Brasil, conduzidas por organismos internacionais. A nova regulação dessas políticas pode ser percebida através da

[...] centralidade atribuída à administração escolar nos programas de reforma, elegendo a escola como núcleo do planejamento e da gestão; o financiamento per capita, com a criação do Fundo de Manutenção e Desenvolvimento do Ensino Fundamental e de Valorização do Magistério (FUNDEF); a regularidade e ampliação dos exames nacionais de avaliação institucional e os mecanismos de gestão escolares que insistem na participação da comunidade (Oliveira, 2005, p. 130)

Desde então, as políticas educacionais têm sido produzidas/produtoras de um discurso de competência do sistema escolar, que visa a um condicionamento do sistema ao mercado, ao mesmo tempo em que propõe modelos gerencialistas de avaliação educacional. A palavra qualidade é ressignificada, passando a atender objetivos mercadológicos, conforme Hypolito esclarece:

[...] No campo da educação, o conteúdo dos discursos hegemônicos na luta pela qualidade de ensino é importado do campo produtivo, reforçando a lógica e a mística da igualdade de mercado, do "deus mercado". A ideologia da qualidade total, fortemente reificada na lógica de mercado, age tanto no campo administrativo-organizacional do processo de trabalho escolar e docente como na reprodução de um "novo modelo disciplinador menos visível" dos 
próprios agentes envolvidos no processo de ensino. Isto é, as políticas neoliberais para a organização da educação têm sido orientadas, em boa parte, para uma conformação (mercadológica) crescente da subjetividade dos agentes educacionais e de sua cultura de trabalho. (Hypolito, 2002, p.278).

Nesse cenário, destaca-se um elemento cujo papel é crucial no conjunto das políticas educacionais: a performatividade que, em acordo com Ball (2004), “funciona de diversas maneiras para 'atar as coisas' e reelaborá-las, permitindo que o Estado se insira profundamente nas culturas, práticas e subjetividades das instituições do setor público e de seus trabalhadores, sem parecer fazê-lo". Além disso, a performatividade atua no deslizamento de significados, produzindo novos perfis profissionais e garante o "alinhamento". Assim, o sentido do trabalho docente dissolve-se em uma noção de práxis ${ }^{2}$ e, também, funciona na lógica do capital, conferindo abertura aos sistemas de gestão ${ }^{3}$ genéricos que visam a "obter" desempenho, melhoria da qualidade e eficácia.

Dessa maneira, a performatividade gera um processo de estranhamento ${ }^{4}$ sobre o trabalho, em que muitos profissionais da educação tornam-se irreconhecíveis para si mesmos. Diante da possibilidade de exercer sua iniciativa individual, os professores, inseridos no funcionamento discursivo do mercado, são capturados por um processo de reificação ${ }^{5}$ em que a força de trabalho do ser humano torna-se objeto, um bem de mercado; e o modo de produção dominante parece adquirir valor vital nas relações sociais e, sob um ponto de vista, impondo a lógica política, ideológica e econômica do capital.

Na dimensão de um novo panopticismo de gestão (de qualidade total e excelência) "o ato de ensinar e a subjetividade do professor sofrem profundas mudanças com as novas formas de controle empresarial” (Idem). Dentre os efeitos causados por essa lógica empresarial, no controle das atividades pedagógicas, destaca-se o desenvolvimento de um processo de individualização crescente, que inclui a destruição das solidariedades baseadas numa identidade profissional comum. Neste cenário, as políticas neoliberais e neoconservadoras buscam, conforme Hypolito e Vieira, "[...] reconstruir a hegemonia conservadora e a consequente legitimação da lógica do mercado, o que irá exigir do professorado uma relativa identificação com as aspirações e necessidades da classe dominante” (2002, p.276), evidenciando-se, assim, valores da cultura-empresa no interior das escolas públicas.

Com isso, as políticas educacionais que organizam e escola e o trabalho docente geram uma série de contradições nos campos de atividades do setor público, provocando, segundo Ball (2004), uma fragilidade nos papéis, nas identidades e nas relações de trabalho que estão sendo criadas em conformidade com uma determinada lógica mercadológica, desencadeando uma nova cultura de performatividade competitiva, a qual envolve uma combinação de descentralização, alvos e incentivos para produzir novos perfis institucionais. O que, mais uma vez, dissipa o discurso de competência do sistema e do professor, condicionando-os aos modelos gerencialistas de controle e de avaliação.

Ademais, observa-se que a concepção de currículo no decorrer das últimas décadas tem acompanhado as reformas neoconservadoras, tomando a forma de uma proposta curricular que prioriza a relevância que conteúdos escolares possam ter para o mercado. No que tange à organização do trabalho docente, observa-se, ainda conforme Hypolito que "o ato de ensinar e

\footnotetext{
${ }^{2}$ Entende-se por práxis, em acordo com o que Vásquez postula em sua obra intitulada Filosofia da práxis, uma atividade humana transformadora da natureza e da sociedade. Nesse plano, a filosofia se torna consciência, fundamento teórico e seu instrumento. A relação entre teoria e práxis é para Marx teórica e prática; prática, na medida em que a teoria, como guia da ação, molda a atividade do homem, particularmente a atividade revolucionária; teórica, na medida em que esta relação é consciente. Nesse sentido, pode-se considerar que a práxis é, portanto, a revolução, ou crítica radical que, correspondendo a necessidades radicais, humanas, passa do plano teórico ao prático. (2007, p. 109, 117)

${ }^{3} \mathrm{~A}$ esse respeito, Ball acrescenta que a gestão apresenta-se como uma ciência promíscua. Não tem relação necessária com substância ou processo. E na medida em que a gestão, no setor público, está se transformando numa função genérica, ela favorece o que Wright (2001) chama de "liderança bastarda" — uma liderança movida pelas preocupações políticas oscilantes do governo e as vicissitudes do mercado educacional. (Ball, 2004).

${ }^{4}$ Através do processo de objetificação do trabalho que, segundo Ball (2004), através da performatividade, objetifica e mercantiliza o trabalho do setor público, e o trabalho com conhecimento (knowledge-work) das instituições educativas transforma-se em "resultados", "níveis de desempenho", "formas de qualidade". (Ball, 2004).

${ }^{5}$ Conforme Marx (1984) [a], na conjuntura do capital o produto do trabalho humano é visto - como mercadoria para a troca - aparece como se tivesse vida própria, autônoma. A reificação é exatamente a relação dos homens mediada por esta coisa - a mercadoria. Os sujeitos (os seres humanos) tornam-se coisas e a coisa (a mercadoria) vira protagonista. As relações sociais passam a ser relações "coisificadas" (reificadas), pois esta é a forma de sociabilidade imposta (conquistada) pelo sistema do capital.
} 
a subjetividade do professor sofrem profundas mudanças com as novas formas de controle empresarial" (Hypolito, 2002, p. 278).

Apresenta-se, assim, um conjunto de práticas e políticas públicas, influenciadas por organismos internacionais, que envolvem e se desenvolvem numa cultura da performatividade docente e, ao mesmo tempo, em disputa nesse território, estão as orientações de cunho democrático que supõem o fortalecimento de práticas de participação, autonomia e descentralização. Por isso, dissolvem-se sentidos, reverberando num processo de desprofissionalização docente e autonomia imaginada.

\subsection{Autonomia imaginada e desprofissionalização docente}

Em tempos de embates multilaterais no campo da discursividade a questão da autonomia docente destaca-se de forma bastante polissêmica, repousando sobre uma variada gama de significações que ora se remetem ao maior controle (porém menos visível) do trabalho docente - o que vem, inclusive, acarretando maior responsabilização desses profissionais - e, ora, como meio de alcance de reais momentos de liberdade para a tomada de decisões pedagógicas. No entanto, ao nos afastarmos de uma possível interpretação ingênua sobre a autonomia docente e, na tentativa de provocar uma reflexão em torno dos recursos discursivos utilizados para produzir este efeito de "liberdade" é que buscamos nos pautar no conceito de autonomia imaginada, conforme proposto por Apple (2000).

Tanto o campo de influência quanto o campo de produção das políticas educativas (Ball, 1994) são permeados por inúmeros recursos discursivos que almejam produzir sentidos de desempoderamento docente. Na atual conjuntura educacional brasileira o investimento à minimização do Estado e a maximização das iniciativas privadas de ordem neoliberal têm realinhado um novo perfil de profissionais docentes. Hypolito sustenta que se trata de um tipo de profissionalismo no qual

não há muito espaço para um aumento de autonomia. O que tem ocorrido é que o controle sobre os fins sociais e políticos da educação - as definições sobre currículo e programas, sobre o que e como ensinar - tem sido, cada vez mais, transferido das professoras para o controle dos gestores, dos políticos e dos interesses econômicos mais amplos. (Hypolito, 2010)

A esse respeito ainda em conformidade com o autor, deparamo-nos diante da possibilidade de a autonomia ser "a terra prometida" (Hypolito, 1999), em que os benefícios para a docência acabam por ilusórios. Nesse sentido, o que se observa em relação ao trabalho docente nas escolas é um processo de autonomia imaginada que interpela esses profissionais à busca de resultados, índices, rankings, afastando-as/os da concepção integral de profissionalismo, condicionando o seu processo de trabalho como mera busca por alcance de resultados isolados das necessidades reais de ensino e aprendizagem. Inclui-se ainda neste processo de desprofissionalização docente a ilusão de que a busca incessante por uma boa colocação no ranking é fator determinante para a profissionalização docente. Frente às "novas" exigências importadas do campo produtivo, os profissionais da educação têm sofrido um processo de minimização de autonomia em seu trabalho diante das políticas públicas regulamentadas por organismos internacionais, seguindo orientações de reformas curriculares e educativas que acompanham reformas neoconservadoras.

Nessa perspectiva, concorda-se com Garcia (2010) quando a autora afirma que estamos diante de um processo em que "o trabalho docente está se transformando em uma ocupação flexível que se caracteriza por habilidades de cunho eminentemente instrumental" (Garcia, p. 234). O que, ainda em acordo com a autora, corrobora com a tese de Freitas, que defende ser este um processo de desprofissionalização docente. Segundo ela, “[...] essa tendência se expressa na medida em que a política pública em si privilegia centralmente a avaliação e a certificação de competências, enfatiza habilidades e conteúdos de cunho eminentemente instrumental relacionados à gestão do ensino e da sala de aula”. (apud Garcia, 2010). 
Com base neste modelo performativo do trabalho docente, percebe-se a ausência do sentido de profissionalismo, em que, segundo Ball, individualmente, mais uma vez, fabricamos a nós mesmos, na tentativa de nos articular dentro dos jogos representacionais de competição, intensificação e qualidade (2010, p. 39).

Tais práticas estão atreladas a um processo de autonomia imaginada, o que irá garantir o desejo de performance por parte do professorado, como se o empreendimento de si sugerisse autonomia ao cumprimento de tarefas pulverizadas via políticas públicas. Ou seja, o próprio sujeito é capturado e produz uma performance que o auto/responsabiliza sobre seu sucesso e/ou fracasso.

Aqui fica mais explícita esta relação entre termos do campo de uma proposta de educação humanizadora sendo utilizado ao lado de vocábulos de lógica produtivista. Trata-se daquilo que Ball (2004) sinaliza como uma nova concepção para o gerenciamento organizacional através de um Estado que governa a distância, inspecionando os sujeitos de formas cada vez menos visíveis e identificáveis.

Estas dissonâncias discursivas, embora menos visíveis e mais ornamentadas no que se refere ao apelo vocabular geram efeitos sobre o trabalho docente. São as novas formas de fabricação do eu, conforme afirma Rose (1998), tratam-se daquelas técnicas que nos capacitam, através de linguagens invisivelmente persuasivas que moldam a conduta, os desejos e objetivos de vida dos seres humanos, configurando-se em um movimento autoavaliativo cujos critérios de avaliação nos são fornecidos por outrem.

Nessa perspectiva, torna-se hegemônico o ideário neoliberal que orienta não apenas as políticas educativas, refletindo no planejamento de uma aula, de um plano de ensino exigindo novas configurações curriculares que sejam totalmente adaptáveis aos valores políticos de consumo, eficiência, competitividade e lucro. Dessa forma, proliferam-se as ambições do processo de regulação não apenas em âmbito macro como também em formas de controle da experiência e existência dos sujeitos.

No entanto, ao considerarmos a precariedade e a contingência do campo da discursividade, há que se produzir formas de resistência por parte dos professores a partir da recontextualização dos discursos oficiais. Cabe salientar aqui, que em conformidade com Ball (2001), iremos incorporar a noção de hibridismo à proposta de recontextualização, partindo-se do pressuposto de que os processos de recontextualização são sobremaneira produtores de discursos híbridos. Ao encontro disso, Lopes destaca que

Não se trata de um processo de assimilação ou de simples adaptação, mas um ato em que ambivalências e antagonismos acompanham o processo de negociar a diferença com o outro. O espaço simbólico da recontextualização passa a ser entendido como um espaço de negociação de sentidos e significados. (Lopes, 2005, p. 59)

E é através do jogo infinito das diferenças que se pode buscar as então entendidas relações de poder oblíquas que favoreçam a produção de novos sentidos profícuos de significação de profissionalização docente e não o seu inverso. Aqui se faz necessário o movimento de deslizamento de sentidos que viabilize a autonomia docente na mudança discursiva necessária para a efetiva problematização das políticas gerencialistas, bem como, no protagonismo por parte destes profissionais na tomada de decisões tanto nas escolhas curriculares como no próprio fazer/criar pedagógico.

Obviamente, trata-se de um caminho árduo cercado de disputas, embates e antagonismos, no entanto, acredita-se que a profissionalização docente carece de novas significações e novas formas de existência que questionem aos imperativos neoconservadores e neoliberais. Nesse sentido, ainda em conformidade com Lopes (2005) "os deslizamentos de sentidos são formas de escape da opressão". Cabe então, aos profissionais da educação, tomarem a posição de sujeitos agentes de práticas discursivas de empoderamento no interior das escolas. 


\section{Considerações Finais}

Diante das discussões apresentadas, compreende-se que os efeitos causados pela lógica empresarial, através do apelo da cultura da performatividade no controle das atividades pedagógicas, destaca-se o desenvolvimento de um processo de individualização crescente, que inclui o empreendimento de si e o arrefecimento das solidariedades baseadas numa identidade profissional comum.

Concluiu-se, portanto, que quando uma cultura performativa opera sobre o trabalho docente, desencadeiam-se sentidos de desprofissionalização, atrelados, sobretudo, a um processo de autonomia imaginada, o que poderá gerar maior controle e adesão por parte do professorado às políticas de responsabilização docente. Nesse sentido, o professor é peça fundamental para o funcionamento discursivo das políticas, haja vista o possível engajamento desse sujeito relacionado, tanto, ao desejo de performance, quanto, para delinear os rumos da recontextualização dessas políticas, as quais poderão conduzir ao sucesso e/ou fracasso escolares.

Na tentativa de confluir projetos antagônicos entre si, o que se sugere é que os professores tenham acesso a esta discussão que vai além das determinações legais e/ou de inculcações de uma ordem neoliberal e neoconservadora no intuito de se tornarem agentes de práticas discursivas de empoderamento no interior das escolas.

Ademais, compreendemos que sem uma análise profunda acerca do contexto social, histórico e político-ideológico em que a educação é produzida minimizam-se as possibilidades de fissuras e lutas por mudanças, distanciando propostas que efetivem a democratização da educação, tanto em relação ao currículo quanto ao trabalho e profissionalização docente.

Finalmente, destacamos que este estudo teve origem nas interlocuções entre os grupos de estudos e pesquisa (CNPQ) ${ }^{6}$ dos autores e almeja ser ampliado em um continuum de investigações, descobertas e diálogos que reflitam sobremaneira sobre os novos desafios impostos ao trabalho docente no período pandêmico desde 2020, no que tange ao processo de trabalho docente, desafios, processos de resistência frente à nova ordem da pedagogia remota, híbrida e as possíveis interferências de tais mudanças na subjetividade do pensar-fazer docente. Empreende-se desde aqui investigações sobre mudanças, reinvenções e resistência ainda mais intensificada á ordem neoliberal e neoconservadora que assola o projeto educacional no cenário nacional.

\section{Referências}

Antunes, R. (1995). Adeus ao trabalho? Ensaios sobre as metamorfoses e a centralidade do mundo do trabalho. Cortez.

Apple, M. (2000). Official knowledge: democratic knowledge in a conservative age. Routledge.

Ball. (2004). Performatividade, privatização e o pós-estado do bem-estar. In: Educação \& Sociedade. Campinas, $25(89)$, 1105-1126. http://www.cedes.unicamp.br.

Ball, S. (1994). Education Reform: A Critical and Post-Structural approach. Buckingham: Open University Press.

Ball. (2010a). Vozes/redes políticas e um currículo neoliberal global. In: Espaço do Currículo, 3(1).

Ball. (2010b). Performatividade e fabricações na economia educacional: rumo a uma sociedade performativa. In: Educação e Realidade, 35(2), 37-55.

Bernstein, B. (1990). A estruturação do discurso pedagógico: classe, códigos e controle. (2a ed.), Vozes.

Brasil, (1988). Constituição da República Federativa do Brasil. Brasília.

Brasil, (1996). Lei n ${ }^{\circ}$ 9.394, de 20 de dezembro de 1996. Estabelece as diretrizes e bases da educação nacional. Brasília, 26 dez.

Brittes. (2013). Democratização da gestão nas escolas públicas brasileiras em uma abordagem discursiva. Revista Exitus, 3, 1-11.

\footnotetext{
${ }^{6}$ Delphos- Grupo de Estudos e Pesquisas em Políticas Educativas, Currículo e Trabalho Docente no âmbito do Instituto Federal Farroupilha Campus Júlio de Castilhos, RS, Brasil; e "Rizoma- Políticas, Currículo e Educação" no âmbito da Universidade Federal de Santa Maria, RS, Brasil.
} 
Research, Society and Development, v. 10, n. 1, e30710111702, 2021 (CC BY 4.0) | ISSN 2525-3409 | DOI: http://dx.doi.org/10.33448/rsd-v10i1.11702

Chiavenato, I. (2000). Introdução à Teoria Geral da Administração. (6a ed.), Campos.

Dagnino, E. (2004). Confluência perversa, deslocamentos de sentido, crise discursiva. In: GRIMSON, A. La cultura en las crisis latinoamericanas. CLACSO, Consejo Latinoamericano de Ciencias Sociales, Ciudad Autónoma de Buenos Aires, Argentina.

Fairclough, N. (2001). Discurso e mudança social. Editora Universidade de Brasília.

Fairclough, N. (2004). Analysing discourse - textual analysis for social research. Routledge.

Garcia. (2010). Textos e contextos na reforma das Licenciaturas: o caso da UFPel. In: Educação e Realidade, 35(2), $229-252$.

Harvey, D. (1998). Neoliberalismo: história e implicações. Edições Loyola.

Hypolito, A. (1999). Trabalho docente e profissionalização: sonho prometido ou sonho negado? In: Veiga, I. P. A.; Cunha, M. I. (Org.). Desmistificando a profissionalização do magistério. Papirus.

Hypolito, A., \& Pizzi, L. C. V. (2002). Reestruturação educativa e trabalho docente: autonomia, contestação e controle. In: Hypolito, A. M. Trabalho docente: formação e identidade. Seiva Publicações.

Hypolito, A. (2010). Políticas curriculares, Estado e regulação. Educação \& Sociedade, Campinas, 31(113), $1337-1354$.

Kuenzer, A. (2002). Caldas, A. Exclusão includente e inclusão excludente - a nova forma de dualidade estrutural que objetiva as novas relações entre educação e trabalho. Lombardi, J. C; Saviani, D.; Sanfelice, J. L. (Orgs.) Capitalismo, trabalho e educação. São Paulo: Autores Associados.

Lopes, A. (2005). Política de currículo: Recontextualização e Hibridismo. Currículo sem Fronteiras. 5(2), 50-64.

Machado, L. (1994). Controle da qualidade total: uma nova gestão do trabalho, uma nova pedagogia do capital. In: Fidalgo, F. S.; Machado, L. R. de S. (orgs.). Controle da qualidade total: uma nova pedagogia do capital. Belo Horizonte: Movimento de Cultura Marxista.

Marx, K. (1984). Teses sobre Feuerbach. In: A ideologia alemã. Edições Avante.

Rose, N. (1998). Governando a alma: a formação do eu privado. In: Silva, T. T. Liberdades reguladas: a pedagogia construtivista e outras formas de governo de eu. Vozes.

Sander, B. (1995). Gestão da Educação na América Latina: construção e reconstrução do conhecimento. Autores Associados.

Sander, B. (2005). Políticas públicas e gestão democrática da educação. Líber Livro.

Triviños, A. (2008). Introdução à pesquisa em ciências sociais: apesquisa qualitativa em educação. Atlas.

Vásquez, A. (2007). Filosofia da práxis. Expressão Popular.

Wood, E. (2003). Democracia contra capitalismo: a renovação do materialismo histórico. Boitempo. 